\title{
Exploring a Gamified Learning Tool in the ESL Classroom: The Case of Quizizz
}

\section{Crystal Callista Anak Yunus ${ }^{1}$ Tan Kim Hua ${ }^{2}$}

'Faculty of Education, Universiti Kebangsaan Malaysia, Selangor, Malaysia.

Email:crystal921214@gmail.com Tel:60194774179

${ }^{\circ}$ Centre for Language Research and Linguistics, Universiti Kebangsaan Malaysia, Selangor, Malaysia.

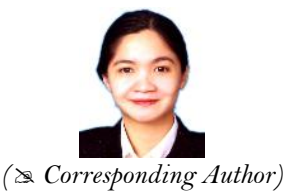

Abstract

Embracing gamification in education is, indeed, inevitable, especially with the arrival of the millennials whose lives are greatly influenced by digital technologies and favor learning in a fun, interactive, and engaging environment. Quizizz, a gamified educational tool, has gradually gained the interest of researchers and stakeholders in education as this application has presented positive outcomes towards learning with the integration of unique game elements such as leader boards, memes, and quiz reports, each of which can assist in enhancing engagement and provide a positive learning experience in a non-stressful setting. This research was conducted to explore the influence and effects of Quizizz in enhancing young Malaysian ESL learners learning irregular English verbs. This quasi-experimentally designed research gathered data from a sample of 30 primary pupils using a pre-test/post-test approach. The data attained were analyzed descriptively using sample t-tests to explain the increment of the pupils' performance on the post-test associated with learning via Quizizz. The results are discussed both in terms of overall pupil performance involving the use of Quizizz and in terms of gender comparison to examine any significant difference in performance between male and female users of Quizizz.

Keywords: Quizizz, Gamified tool, Gamification, Game elements, Irregular verbs, Second language.

Citation | Crystal Callista Anak Yunus; Tan Kim Hua (2021). Exploring Gamified Learning Tool in ESL Classroom: The Case of Quizizz. Journal of Education and e-Learning Research, 8(1): 103Quiziz History:

Received: 30 November 2020

Revised: 21 December 2020

Accepted: 25 January 2021

Published: 8 February 202

Licensed: This work is licensed under a Creative Commons Attribution 3.0 License $(\mathrm{cc}) \mathbf{E Y}$

Publisher: Asian Online Journal Publishing Group
Acknowledgement: Both authors contributed to the conception and design of the study.

Funding: This study received no specific financial support.

Competing Interests: The authors declare that they have no conflict of interest.

Transparency: The authors confirm that the manuscript is an honest, accurate, and transparent account of the study was reported; that no vital features of the study have been omitted; and that any discrepancies from the study as planned have been explained.

Ethical: This study follows all ethical practices during writing.

\section{Contents}

1. Introduction 


\section{Contribution of this paper to the literature}

This study contributes to existing literature by exploring the influence and effects of Quizizz in enhancing young Malaysian ESL learners learning irregular English verbs.

\section{Introduction}

In Malaysia, the English language is considered a second language and can be viewed as a foreign language by citizens who have limited exposure to English. The acquisition of the English language is greatly emphasized in the Malaysian education system, whereby it is taught as a compulsory subject in elementary, secondary, and tertiary education. Although the English language is strongly highlighted in the education system, Malaysians are still far from achieving the aspirations of the country to have a nation that is proficient in the English language. The declining standard of the English language in Malaysia is not only a major concern in the education system but is also significant in meeting the demands of globalization in education. To elevate the English language standard in Malaysia, the Malaysian education ministry has made a major effort to place great emphasis on digital learning to not only enhance the effectiveness of English language teaching and learning but also to integrate elements of the fourth industrial revolution into the classroom.

With the advent of the fourth industrial revolution, teachers hold a responsibility to prepare younger generations to acquire essential skills such as digital competency, problem-solving skills, and creative and critical thinking, as well as instill a sense of ownership in their learning. Game-based learning via online interactive games is a modern, relevant, and effective means of imparting crucial knowledge and skills needed to sustain mankind's current lifestyle, which is greatly influenced by the use of Information and Communication Technologies (ICT). In this respect, current education in Malaysia is now shifting from conventional teaching and learning to a modern approach of integrating ICT with an emphasis on 21 st Century Learning to equip younger generations with the essential skills needed to survive in this world of advancement.

According to Yunus and Azman (2019), teachers these days are 'forced' to shift their pedagogy practices as these practices are much influenced by an ever-updating technology. Online gaming is becoming a preference for millennials due to its mobility, flexibility, and versatility, as well as providing interaction without borders. Gamification was brought to educational prominence by Pelling (2011) whose work led to the creation of various interactive applications for learning, including Quizizz, Kahoot!, Quizlet, and Plickers. Online interactive games provide opportunities for learners to be independent seekers of knowledge as well as to equip themselves with relevant skills in the current lifestyle of humankind, which is gradually revolving around the world of ICT. Cheng and $\mathrm{Su}$ (2012) state that game-based learning can make learners become the center of learning and make the learning process easier, more interesting, and more effective. This is in line with the principles of twenty-firstcentury learning, which places great emphasis on student-centered learning and promotes the use of learning experiences that are fun and engaging.

There have been numerous previous studies showing positive implications whereby gamification is effective in enhancing learners' engagement and motivation in learning. Studies on the use of Quizizz to enhance English grammar learning has been explored in an international context, but there has been limited local research done on how Quizizz impacts irregular past verb learning among young English as Second language (ESL) learners in Malaysia. Irregular past verbs are, indeed, one of the more challenging grammar elements to be acquired by learners who learn English as a second or foreign language. In the Malaysian context, the acquisition of regular past verbs and irregular verbs is a whole new knowledge base to be explored by Malaysian learners. The absence of past tense in the official Malay language makes it much more challenging for Malaysian learners to acquire this crucial knowledge. Overgeneralization of the inflections for regular past verbs into irregular past verbs is a common mistake made by Malaysian learners and most ESL users. To address this concern, game-based learning via online interactive games such as Quizizz in the Malaysian English language primary ESL classroom presents new, positive outcomes whereby learning English irregular verbs can be exhilarating and rewarding, especially when it comes to imparting knowledge to millennials.

\section{Literature Review}

\subsection{Gamification concepts}

The world of education is now encountering the demands of inculcating digital competency and twenty-firstcentury skills to all mankind in order to able to function well in the emerging fourth industrial revolution. This has led to the integration of gamification into the education system in the hope of honing essential skills among learners. Various definitions are used by different researchers to explain the meaning and purpose of gamification. Deterding, Dixon, Khaled, and Nacke (2011) state that "gamification is the use of game design elements in nongame contexts" (p.9). Kapp (2012) implies that gamification employs game thinking, methods, and elements in a setting that varies from the games. Marczewski (2013) states that gamification is the application of game metaphors, game elements, and concepts in settings that differ from games that aim to boost motivation and affect desirable player conduct. The definitions stated by various researchers hold that game elements like empowerment, engagement, and commitment are unique features in gamification that distinguish it from serious games that focus more on training to achieve a predetermined goal or outcome.

The distinctive game elements in gamification play a crucial role, not only in accelerating learners' determination to complete the assigned tasks but also by increasing their motivation to progress by offering positive reinforcement like badges or reward points. Flores (2015) in his research on gamification in second language learning, states that the key objectives of gamification focus on increasing user participation and enhancing user motivation by integrating game elements and strategies, for instance, leaderboards and prompt feedback. The availability of these features will foster a sense of empowerment and boost user engagement during their attempts in designated tasks to accomplish their targeted goals in their learning. 


\subsection{Gamification in education and second language learning}

Embracing gamification in education is inevitable to solidify the teaching and learning experiences in the $21^{\text {st }}$ century. Over the years, education has experienced drastic transitions from chalk and talk to computer hardware and software along with web-based technologies designed for instruction. Mankind has experienced the evolution of education with the emergence of various teaching methods to accommodate the distinctive needs and demands of different generations. According to Prensky (2001), most learners are digitally literate and differ in the ways they learn and process information. In the era of the fourth industrial revolution, the millennial generation exchanges information via social networking and blogging. To cater to the needs of this type of learner, educators are urged to use ICT, Mobile Learning resources, and game-based learning to maximize the effect of instruction.

Gamification in second language learning has been a subject of interest in numerous researches and discussions about its application, especially with the growing use of technology in education. The goal of incorporating gamification into education is to present a more engaging, attractive, and effective learning experience for the student. In the context of second language learning, students might find it frustrating and demotivating to learn a second language due to a lack of exposure to the living language and to varieties of learning experiences. To engage the interest of L2 learners, gamification offers a fun, interactive, and non-threatening learning environment. Over the years, technology has been immersed into L2 education to enhance the quality of the teaching and learning experience. Flores (2015) states that "In order to change or set off a specific behavior, the learners need to be motivated and gamification opens the door for the L2 learner to enhance their language learning experience and at the same time acquire the skill to solve any task or challenge the class, the unit, or what the topic presents." This concurs with several methodologies and techniques in L2 teaching whereby learners learn best when they are motivated, engaged, and gain a sense of empowerment in their learning.

\subsection{Quizizz: an overview and past studies}

Ideally, games are associated with exhilaration, engagement, and competitiveness, as well as presenting opportunities for social interaction and self-expression in a non-threatening environment. It is worthwhile to explore the potentials of gamified educational applications to facilitate the giving of instructions and to enhance learning experiences. Flores (2015) as cited in Rahayu and Purnawarman (2018), mentions that "Gamification aims to increase participation and motivate users through the use of game elements such as points, leaderboards, and immediate feedback, among other things." Basuki and Hidayati (2019) explain that "Quizizz is a fun multiplayer game platform or application classroom activity for quiz-games in which students become the controller of their pace of game classroom activity." The establishment of gamification elements in Quizizz like leaderboards, time limits, points, and social relatedness all enhance the user's participation and determination and also provide a sense of empowerment in completing the assigned task.

Several studies have been done on the application of Quizizz in education, and the results show positive outcomes. A study conducted by Zhao (2019) examined the use of Quizizz in an accounting classroom to integrate fun learning. According to the author of this study, the students enjoy Quizizz, whereby the inclusion of fun and interactive elements helps in sustaining their attention. The students expressed that their favorite feature of Quizizz was the leader board as it excites them to compete and strive for improved performance. Another study carried out by Ju and Adam (2018) studied Quizizz as a game-based in an Arabic classroom. The results of this research showed a high percentage of positive points towards the application of Quizizz during the Arabic class as they found that Quizizz is a significantly positive tool in learning institutes as students are more interested and focused on the class. Comparative research was done by Basuki and Hidayati (2019) that compares students' perspectives on two online educational quizzes, namely 'Kahoot!' and 'Quizizz. The findings of this study showed the learners believe that Quizizz is a better choice for web-app online quizzes than Kahoot! Though with many shreds of evidence that showed Quizizz has the potential to enhance interest and motivation, there is not enough positive data to lead us to regard Quizizz as an effective and suitable tool in language instruction and acquisition. To advocate that Quizizz is a beneficial and effective learning instrument for improving language teaching and learning, there is a need to examine its impact, thus providing useful insights to all stakeholders in the education line.

\section{Methodology}

The single group pre-test post-test design was employed in this research. Pre-test and post-test were executed before and after the treatment. The tests were conducted to obtain the scores, which will be used to assess the participants' achievements both before and after the intervention, as well as to make gender comparisons of learner performance.

Samples of 30 primary school pupils of 11 years of age were selected, comprising of 19 boys and 11 girls. The unequal numbers of male and female respondents were the outcome of purposive sampling whereby struggling pupils were chosen to examine whether Quizizz assisted the participants in enhancing their learning of irregular past verbs. The goal was as also to unravel the impact of Quizizz in the respondents' interest and performance in the targeted language structure. This study was conducted in a primary school in Padawan, Sarawak. Apart from that, this study was conducted on the first term of schooling when the respondents received formal learning on the usage of regular past and irregular verbs.

The first research question was answered by analyzing the scores of each respondent in pre-test and post-test. The scores for both tests were then translated into percentages. Descriptive statistics were used to display the data collected to answer the first research question. Mean score and mean interest of the population were obtained via the IBM SPSS Statistics Version 23 application.

A normality test was conducted before answering the second research question so as to select appropriate tests with regards to the data attained. The result of normality tests on both scores are displayed in Table 1 . Nonparametric tests were conducted for this research as the data was not normally distributed due to $\mathrm{p}<0.05$ for both scores obtained on Kolmogorov-Smirnov $(\mathrm{N}>50)$. The second research question was answered using a MannWhitney $\mathrm{U}$ test to describe the relationship between the gender for post-test marks. 
Table-1. Normality test.

\begin{tabular}{|c|c|c|c|c|c|c|}
\hline & \multicolumn{3}{|c|}{ Kolmogorov-Smirnov $^{a}$} & \multirow[b]{2}{*}{ Statistic } & \multirow{2}{*}{$\begin{array}{c}\text { Shapiro-Wilk } \\
\text { df } \\
\end{array}$} & \multirow[b]{2}{*}{ Sig. } \\
\hline & Statistic & df & Sig. & & & \\
\hline Pre-Test & 0.190 & 30 & 0.007 & 0.873 & 30 & 0.002 \\
\hline Post-Test & 0.282 & 30 & 0.000 & 0.777 & 30 & 0.000 \\
\hline
\end{tabular}

\subsection{Research questions}

Considering the significance of irregular past verbs learning in enhancing English language acquisition among young ESL learners, this study attempts to seek answers to the following research questions:

1. Does using Quizizz enhance primary education pupils' learning of irregular past tense verbs?

2. Does using Quizizz make any significant difference to the learning of irregular past tense verbs among primary male and female pupils?

\section{Findings}

4.1 Research question 1

Does using Quizizz enhance primary grade 5 pupils' learning of irregular past tense verbs?

The raw data attained from the pre-test and post-test were analyzed descriptively by displaying the data in both graphic and tabulation forms. The descriptive data were calculated, and pie charts were formulated to display the frequency of marks for both pre-test and post-test, as well as the mean score of interest.

\begin{tabular}{l|c|c}
\multicolumn{2}{c}{ Table-2. Summary on descriptive statistics of variable involved. } \\
\hline & Pre-test & Post-test \\
\hline N Valid & 30 & 30 \\
\hline Missing & 0 & 0 \\
\hline Mean & 62.0000 & 86.6667 \\
\hline Median & 60.0000 & 85.0000 \\
\hline Mode & 60.00 & 100.00 \\
\hline Std. Deviation & 13.9951 & 12.9544 \\
\hline Minimum & 40.00 & 70.00 \\
\hline Maximum & 80.00 & 100.00 \\
\hline Sum & 1860.00 & 2600.00 \\
\hline
\end{tabular}

Based on the summary in Table 2 above, three variables are being studied in this research, which are pre-test and post-test marks. Pre-test marks were collected before playing Quizizz, and post-test marks were collected after playing Quizizz, while mean interest was calculated from the Likert Scale.

Pre-test marks were from sample data from the 30 respondents, with none missing a value. The average marks were 62 for the pre-test, while the mid-value, known as the median, was 60. The mode was 60. The dispersion of the data in standard deviation was 13.995 , which we can say is close to the mean of the data. The respondents' marks for the pre-test ranged from 40 to 80 .

Next, post-test marks were also from sample data from the 30 respondents, with none missing a value. The mean for the 30 pupils was 86.67 , while the mid-value, known as the median, was 85 . The mode was 100 . The dispersion of the data in standard deviation was 12.954 , which we can say is close to the mean of the data. The respondents' marks for the pre-test ranged from 70 to 80.

\section{Pre Test Mark}
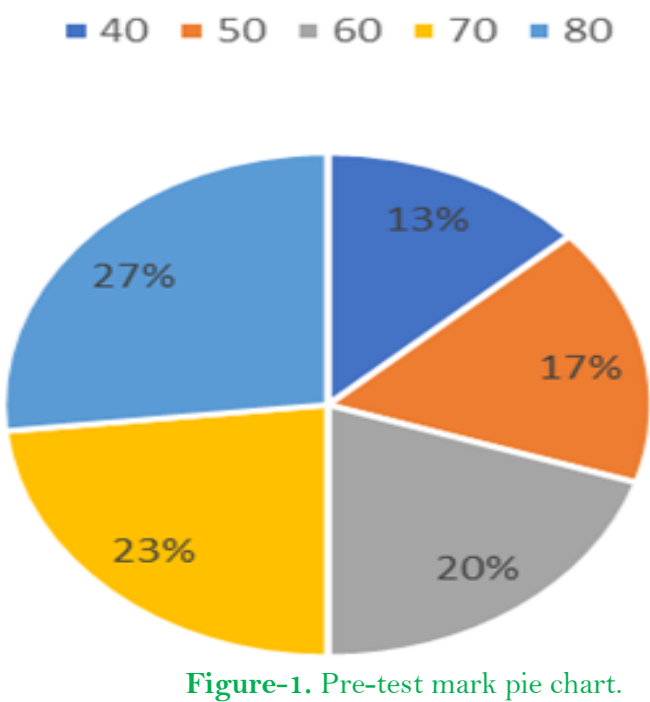

Figure 1 above is the pie chart of pre-test marks showing the frequency of the marks. As mentioned earlier, the range was from 40 to 80 marks. The highest marks were from $13 \%$ of the 30 pupils, which means only a few of them got 80 marks for their pre-test. The lowest marks were from $27 \%$ of the respondents, which was the highest frequency, concluding that most of the respondents got 40 marks for their pre-test. 


\section{Post Test Mark}

$=70=80=90=100$

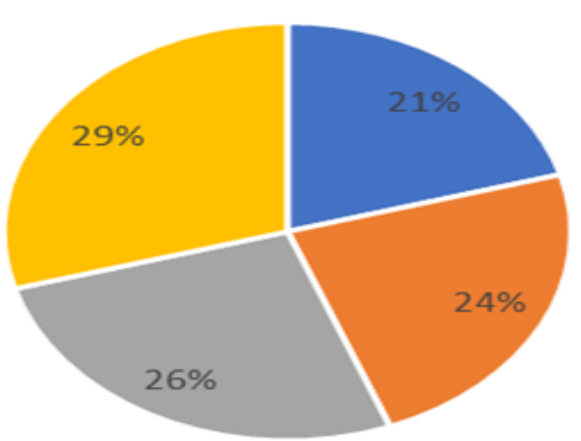

Figure-2. Post-test marks pie chart.

Figure 2 above is the pie chart of post-test marks showing the frequency of the marks. As mentioned earlier, the range was from 70 to 100 marks. The highest marks were from $29 \%$ of the 30 respondents, which was the highest frequency for all the post-test marks. The lowest marks were from $21 \%$ of the respondents, which was the lowest frequency, concluding that the respondents' post-test marks had improved on the pre-test marks.

It can be concluded from the above section that there is a difference in the mean of the pre-test and post-test marks. The post-test marks increase from 62 to 86.67. There is a difference in the range of both pre-test and posttest marks. The Pre-test minimum marks were 40, while the post-test minimum marks were 70 . These show that using Quizizz enhanced primary grade 5 pupils' learning of irregular past tense verbs.

\subsection{Research question 2}

Does using Quizizz make any significant difference to the learning of irregular past tense verbs among primary grade 5 male and female pupils?

This research aimed to determine whether there was any significant difference in the learning of irregular past tense verbs between primary level male and female pupils. Based on the data obtained earlier, the results from the Kolmogorov-Smirnov rejected the Ho because the significant value of both post-test and mean interest is 0 , which is less than alpha value 0.05. This is because the distribution of scores for both groups of the independent variable of male and female respondents presented a contradiction in the value assumption of normality. Hence, an analysis of a Mann-Whitney U test was used to determine if there was a significant difference in the learning of irregular past tense verbs among primary school male and female pupils. Based on the research question, null and alternative hypotheses derived in accord to the question were:

$H_{0}$ : There is no significant gender difference in the pupils' performance.

$H_{1:}$ There is a significant gender difference in the pupils' performance.

\begin{tabular}{l|c|c|c|c}
\hline \multicolumn{5}{c}{ Table-3. Mann-Whitney U test. } \\
\hline & Gender & N & Mean Rank & Sum of Ranks \\
\hline \multirow{4}{*}{ Mean Interest } & Boy & 19 & 14.08 & 267.50 \\
\cline { 2 - 5 } & Girl & 11 & 17.95 & 197.50 \\
\cline { 2 - 5 } & Total & 30 & & \\
\hline \multirow{3}{*}{ Post-Test } & Boy & 19 & 13.03 & 247.50 \\
\cline { 2 - 5 } & Girl & 11 & 19.77 & 217.50 \\
\cline { 2 - 5 } & Total & 30 & & \\
\hline
\end{tabular}

\begin{tabular}{l|c}
\hline & Post-Test \\
\hline Mann-Whitney U & 57.500 \\
\hline Wilcoxon W & 247.500 \\
\hline Z & -2.147 \\
\hline Asymp. Sig. (2-tailed) & .032 \\
\hline Exact Sig. [2*(1-tailed Sig.)] & $.042^{\mathrm{b}}$ \\
\hline
\end{tabular}

Based on table 3 above, it can be concluded that there is a significant difference between the genders for posttest marks $(\mathrm{U}=57.5$, p-value $=0.32)$. Females had higher post-test marks than males.

\section{Discussion}

\subsection{The impact of Quiziz: on pupils' learning of irregular past tense verbs}

As mentioned in the methodology section, there were ten multiple-choice questions in total in both pre-test and post-test. The raw scores for both tests were analyzed to obtain mean scores to make a comparison, which was then used to describe whether the implementation of Quizizz had positively impacted the respondents' learning of irregular past verbs. The mean scores for both tests, as demonstrated in Table 2, showed an increment in the pupils' performance before and after using Quizizz in their learning on irregular past verbs from a mean score of 62.00 to 86.67. The test results reflected that the implementation of online games like Quizizz has brought about an enhancement in the pupils' learning of irregular past tense verbs. Based on previous studies by Baturay, Yildirim \& Daloglu (as cited in Donmus (2010), "using computers and the web in language teaching provides more effective learning when compared with traditional methods, increases the motivation of the learner, develops positive 
attitudes in students, and increases the retention process." Hence, it can be concluded that the use of Quizizz does assist in enhancing pupils' learning of irregular past tense verbs.

\subsection{Gender comparison of pupils' learning of irregular past tense verbs}

Table 3 demonstrates the results of gender comparison for post-test marks with a reading of $\mathrm{U}=57.5$, $\mathrm{p}$-value $=$ 0.32. This indicates that there was a significant difference between the genders for post-test marks, and therefore, the null hypothesis is rejected in favor of the alternative hypothesis. Girls showed a greater improvement in their learning of irregular past verbs via Quizizz, with the mean score of post-test $(M=19.77)$ being higher than boys $(\mathrm{M}=13.03)$. Based on this result, there is a need to devise suitable approaches and teaching strategies to bridge the gap between genders and their acquisition of irregular past verbs. According to Wilsenach and Makaure (2018) it is indeed crucial as numbers are rising, showing boys being left behind in the field of education. Hence, the researcher ought to explore various engaging and invaluable learning activities that can accommodate the distinctive needs and abilities for both genders which also lead to the establishment of equity in their learning experience. Hwang, Hong, Cheng, Peng, and Wu (2013) suggested that male learners prefer game-based learning tool featuring story lines and role-playing that serve as guidelines in their learning and arouse better performance than female counterparts in types of game designs. This is also reflected in the findings of Wang and Wang (2008) who discovered that male learners display higher pleasure and satisfaction when playing Massively Multiplayer Online Role-Playing Games (MMORPGs) which highlight cooperative learning. The element of role-playing and storyline are not featured in Quizizz which could be the missing source of motivation to boost male pupils in performing better or as good as the female pupils in this study.

\section{Conclusion}

Based on the findings attained from this research, the use of Quizizz is not only effective in enhancing the teaching and learning of English irregular past verbs among young ESL learners but also serves as an invaluable tool to inculcate interest and a sense of passion towards acquiring the English language. The implementation of online interactive games such as Quizizz can be seen as an exhilarating, creative, and impactful means of shifting from the conventional way of imparting knowledge, especially to millennials. The findings of this research indicate that game-based learning is indeed beneficial in language teaching as it is effective in elevating the pupils' interest and learning of the English irregular past verbs. Gamification also prepares both teachers and pupils to meet the demands of globalization in education. Online interactive games are relevant and useful not only to enhance the quality of language teaching, but also to promote digital literacy among the young generation, which is in line with the demands of the fourth industrial revolution.

\section{References}

Basuki, Y., \& Hidayati, Y. (2019). Kahoot! or quizizz: The students' perspectives. Retrieved from: https://doi.org/10.4108/eai.27-42019.2285331.

Cheng, C. H., \& Su, C. H. (2012). A Game-based learning system for improving student's learning effectiveness in system analysis course. Procedia-Social and Behavioral Sciences, 31, 669-675.Available at: https://doi.org/10.1016/j.sbspro.2011.12.122.

Deterding, S., Dixon, D., Khaled, R., \& Nacke, L. (2011). From game design elements to gamefulness: Defining gamification. Paper presented at the Proceedings of the 15th International Academic MindTrek Conference: Envisioning Future Media Environments. ACM.

Donmus, V. (2010). The use of social networks in educational computer-game based foreign language learning. Procedia-Social and Behavioral Sciences, 9, 1497-1503.Available at: https://doi.org/10.1016/j.sbspro.2010.12.355.

Flores, J. F. F. (2015). Using gamification to enhance second language learning. Digital Education Review, 27, 32-54.

Hwang, M. Y., Hong, J. C., Cheng, H. Y., Peng, Y. C., \& Wu, N. C. (2013). Gender differences in cognitive load and competition anxiety affect 6th grade students' attitude toward playing and intention to play at a sequential or synchronous game. Computers $\mathcal{E}^{\circ}$ Education, 6O(1), 254-263.Available at: https://doi.org/10.1016/j.compedu.2012.06.014.

Ju, S. Y., \& Adam, Z. (2018). Implementing quizizz as game based learning in the Arabic classroom. European Journal of Social Science Education and Research, 5(1), 194-198.Available at: https://doi.org/10.2478/ejser-2018-0022.

Kapp, K. (2012). The gamification of learning and instruction game-based methods and strategies for training and education. San Francisco, CA: Pfeiffer.

Marczewski, A. (2013). What's the difference between Gamification and Serious Games? Retrieved from Gamasutra: http://www.gamasutra.com/blogs/AndrzejMarczewski/20130311/188218/Whats_the_diffeence_between_Gamification_ and_Serious_Games.php.

Pelling, N. (2011). The (short) prehistory of "gamification” . . . [Blog post]. Retrieved from: http://nanodome.wordpress.com/2011/08/09/the-short-prehistory-ofgamification/. On line.

Prensky, M. (2001). Digital natives, digital immigrants. In on the Horizon, October 2001, 9 (5). Lincoln: NCB University Press.

Rahayu, I. S. D., \& Purnawarman, P. (2018). The use of quizizz in improving students' grammar understanding through self-assessment. Advances in Social Science, Education and Humanities Research, 254, 102-106.

Wang, H.-Y., \& Wang, Y.-S. (2008). Gender differences in the perception and acceptance of online games. British Journal of Educational Technology, 39(5), 787-806.

Wilsenach, C., \& Makaure, P. (2018). Gender effects on phonological processing and reading development in Northern Sotho children learning to read in English: A case study of Grade 3 learners. South African Journal of Childhood Education, 8(1), 1-12.Available at: https://doi.org/10.4102/sajce.v8i1.546.

Yunus, M. M., \& Azman, M. A. (2019). Memory stay or stray? : Irregular verbs learning using kahoot! Arab World English Journal (AWEJ) Special Issue on CALL, 5, 206-219.

Zhao, F. (2019). Using quizizz to integrate fun multiplayer activity in the accounting classroom. International Journal of Higher Education, 8(1), 37-43.Available at: https://doi.org/10.5430/ijhe.v8n1p37. 